\title{
Solar urticaria related to ultraviolet nail lamps: a case report
}

\author{
Katrien Coninx', Olivier Aerts², An Bervoets ${ }^{1,2}$
}

\author{
${ }^{1}$ Department of Dermatology, University Hospital Leuven, Belgium, ${ }^{2}$ Department of Dermatology, University Hospital \\ Antwerp, Belgium
}

Corresponding author: Dr. Katrien Coninx, E-mail: katrienconinx@hotmail.com

\begin{abstract}
Solar urticaria is a rare chronic skin condition triggered via (an) uncharacterized chromophore(s) and characterized by skin lesions and/or itch immediately after sun exposure. We present a 50-year-old woman who presented to us with a history of an itchy and burning sensation after a few minutes of sun exposure, first noticed after applying gel nails for the first time. We suggest that a photoallergen can be formed during the polymerization and hardening process of gel nails.
\end{abstract}

Key words: Solar urticaria; Ultraviolet nail lamps; Gel nails; Pathogenesis; Case report

\section{INTRODUCTION}

Solar urticaria is an idiopathic rare immunoglobulin $\mathrm{E}(\mathrm{IgE})$-mediated photodermatosis with a largely hypothetical pathogenesis. A reaction between a precursor factor in the skin and an action spectrum is assumed [1]. We report a case of solar urticaria in which ultraviolet (UV) nail lamps are thought to be the trigger for solar urticaria. The intense effect of UVA exposure may provoke initial sensitization to an emerging photoallergen in sun-sensitive people. Further research is needed to investigate the process of emerging photoallergens in solar urticaria.

\section{CASE REPORT}

A 50-year-old woman noticed tingling of her hands after applying gel nails for the first time, ten months before the first consultation. This sensation returned after every application accompanied with pruritus and a burning sensation. In spring, she developed an itching and burning sensation on head, arms and legs. After a few minutes of sun exposure, she immediately developed an erythema on sun-exposed areas. These symptoms decreased a little bit after taking antihistamines (cetirizine). Later in spring, she noticed a feeling of swelling and discovered redness in the neck. The itchy feeling persisted and she also experienced symptoms on cloudy days, but not behind glass. The symptoms did not improve during summer. The general practitioner prescribed ebastine $20 \mathrm{mg}$, bilastine $20 \mathrm{mg}$ and cetirizine $20 \mathrm{mg}$ without any improvement. A neurological examination revealed no cause for the tingling sensation. There were no other systemic symptoms reported. She also reported that the rash always started at her fingers. The patient took daily progesterone $200 \mathrm{mg}$, paroxetine $10 \mathrm{mg}$, levothyroxine $100 \mu \mathrm{g}$, lorazepam $1 \mathrm{mg}$ and alendronic acid with cholecalciferol once weekly. Contact allergy and photo contact allergy were excluded by (photo) patch tests with the Belgian standard series, cosmetic test series, drug test series, photo patch test series and own products and contents. The tests revealed positivity for nickel, cobalt and an unclear reaction to limonene and linalool hydroperoxides. These results couldn't explain the lesions. Eventually, she was referred to our specialized center to perform monochromatic phototesting to exclude any form of light allergy. We excluded cutaneous porphyria's by analyzing the heme synthesis (Table 1). Blood porphyrin analysis revealed free erythrocyte porphyrin levels of $1278 \mu \mathrm{g} / \mathrm{L} \mathrm{RBC}$ with a normal PPIX/ZNPP ratio and normal plasma

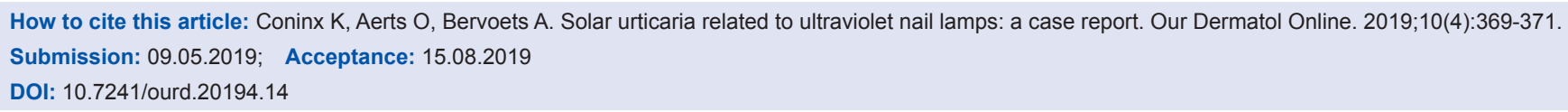


porphyrin, excluding the diagnosis of Erythropoietic Protoporphyria. The clinical findings and phototesting (Figs. 1 and 2) suggested the diagnosis of solar urticaria with a reduced minimal erythema dose (MED) of $10 \mathrm{~J} / \mathrm{cm}^{2}$ at $350 \pm 10 \mathrm{~nm}$ (UVA spectrum) and a strong erythemal flare reaction immediately

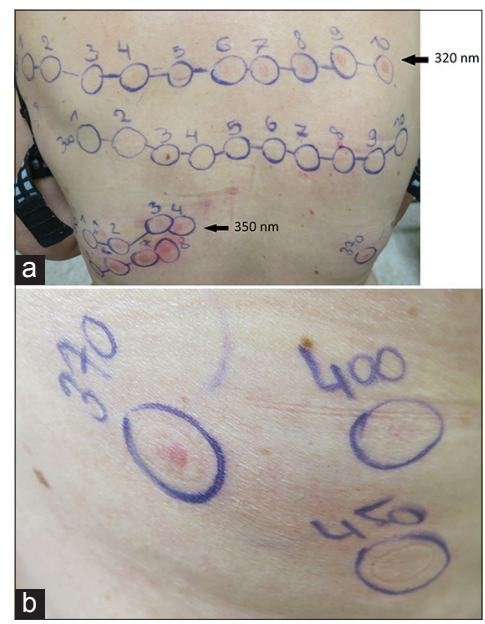

Figure 1: (a) At $350 \mathrm{~nm}$, a strong erythemal flare reaction is visible immediately after irradiation. This clinical sign is very suggestive for the diagnosis of solar urticaria. (b) Details of the irradiation zones of 370,400 und $450 \mathrm{~nm}$ immediately after irradiation. A clearly visible urticarial plaque is seen at $370 \mathrm{~nm}$.

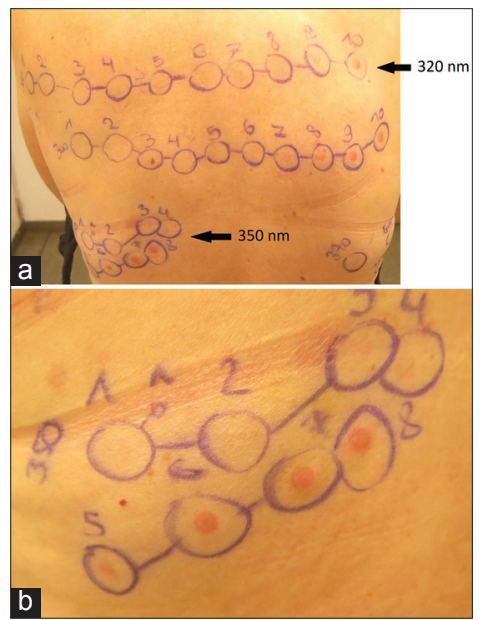

Figure 2: (a) 24 hours after irradiation a reduced MED of $40 \mathrm{~mJ} / \mathrm{cm}^{2}$ at $300 \mathrm{~nm}$ and of $2 \mathrm{~J} / \mathrm{cm}^{2}$ at $320 \mathrm{~nm}$ is visible. At $370 \mathrm{~nm}$ an erythemal response is visible. (b) 24 hours after irradiation, the strong reaction has disappeared. Reduced MED of $10 \mathrm{~J} / \mathrm{cm}^{2}$ is visible in the UVArange $(350 \mathrm{~nm})$.

Table 1: Analysis of the Heme synthesis with free erythrocyte porphyrin, zinc-chelated protoporphyrin (ZnPP), free protoporphyrin (PPIX) and plasma porphyrin

\begin{tabular}{lcc}
\hline Test & Levels & Reference limits \\
\hline Free erythrocyte porphyrin & $1278 \mu \mathrm{g} / \mathrm{L}$ RBC & $200-550 \mu \mathrm{g} / \mathrm{L}$ RBC \\
Zinc-chelated protoporphyrin (ZnPP) & $48 \%$ & \\
Free protoporphyrin (PPIX) & $52 \%$ & \\
Plasma porphyrin & negative & \\
\hline
\end{tabular}

(c) Our Dermatol Online 4.2019 after radiation (Table 2 and 3). The term MED as a measure of erythemal radiation is not a standard measure as normal ranges are highly dependent on individual sensitivity, characteristics of the source, determinants of the exposure, nature of the skin and observational factors. The reference limits are specific to a particular investigating center, these tables show the reference limits in our center [2]. We suggested protection with sunscreens, clothing, a hat and sunglasses. We also suggested continuing the treatment with antihistamines, but, if insufficient, UVB therapy thrice weekly with gradually increasing the dose was proposed.

\section{DISCUSSION}

In the context of investigation of photosensitivity the patient was already tested for (photo)contact allergy. She did not take any medications known to cause phototoxicity. Familial history revealed no affected members. The clinical history of the time course, absence of hardening and swelling are also suggestive for solar urticaria. To complete the proper investigation of photosensitivity, the patient was tested with a monochromator (LOT Oriel Group Europe, Germany) in order to identify the correct minimal erythema dose and action spectrum. She developed a strong urticarial reaction immediately after irradiation in the UVA range, indicating a very low minimal urticarial dose (MUD) in these range. Consequently, we diagnosed the patient with solar urticaria with action spectrum in the UVA range.

A reaction between a precursor factor in the skin and an action spectrum is assumed in literature [1]. The resulting photo allergen induces immunoglobulin E production triggering mast cell degranulation, an erythematous flare reaction and wheals or itch appear as a result of type I allergy [3,4]. During the diagnostic process, we were surprised by the coincidence of the use of gel manicure systems and UV nail lamps and the development of solar urticaria. In the case of gel manicure systems, different acrylate monomers constitute together a nail polish, requiring UV light for polymerization and hardening, mostly in a wavelength range of 340-380 nanometer, in the UVA range $[5,6]$. The UVA radiation is necessary to let the artificial nail coating polymerize. In relation to the accepted pathogenesis of solar urticaria, it is remarkable that the patient developed solar urticaria in the range of the used UV nail lamp (365nm). During a sensitization 
Table 2: Minimal erythema dose (MED) test 24-hour after irradiation

\begin{tabular}{|c|c|c|c|c|c|c|c|c|}
\hline & \multicolumn{8}{|c|}{ Wavelength \pm margin of error (bandwidth) } \\
\hline & $300 \pm 2.5 \mathrm{~nm}$ & $320 \pm 5 n m$ & $350 \pm 10 \mathrm{~nm}$ & $370 \pm 10 \mathrm{~nm}$ & $400 \pm 10 \mathrm{~nm}$ & $450 \pm 10 \mathrm{~nm}$ & $500 \pm 10 \mathrm{~nm}$ & $600 \pm 10 \mathrm{~nm}$ \\
\hline & $5 \mathrm{~nm}$ & $10 \mathrm{~nm}$ & $20 \mathrm{~nm}$ & $20 \mathrm{~nm}$ & $20 \mathrm{~nm}$ & 20nm & $20 n m$ & $20 \mathrm{~nm}$ \\
\hline Patient & $40 \mathrm{~mJ} / \mathrm{cm}^{2}$ & $2 \mathrm{~J} / \mathrm{cm}^{2}$ & $10 \mathrm{~J} / \mathrm{cm}^{2}$ & + & - & - & - & - \\
\hline Normal & $20-50 \mathrm{~mJ} / \mathrm{cm}^{2}$ & $2-5 \mathrm{~J} / \mathrm{cm}^{2}$ & $20-50 \mathrm{~J} / \mathrm{cm}^{2}$ & - & - & - & - & - \\
\hline
\end{tabular}

Table 3: MED-test immediately after irradiation

\begin{tabular}{|c|c|c|c|c|c|c|c|c|}
\hline & \multicolumn{8}{|c|}{ Wavelength \pm margin of error (bandwidth) } \\
\hline & $300 \pm 2.5 \mathrm{~nm}$ & $320 \pm 5 \mathrm{~nm}$ & $350 \pm 10 \mathrm{~nm}$ & $370 \pm 10 \mathrm{~nm}$ & $400 \pm 10 \mathrm{~nm}$ & $450 \pm 10 \mathrm{~nm}$ & $500 \pm 10 \mathrm{~nm}$ & $600 \pm 10 \mathrm{~nm}$ \\
\hline & $5 \mathrm{~nm}$ & $10 \mathrm{~nm}$ & $20 \mathrm{~nm}$ & $20 \mathrm{~nm}$ & $20 \mathrm{~nm}$ & $20 \mathrm{~nm}$ & $20 \mathrm{~nm}$ & $20 \mathrm{~nm}$ \\
\hline Patient & - & $1 \mathrm{~J} / \mathrm{cm}^{2}$ & $5 \mathrm{~J} / \mathrm{cm}^{2}$ & + & - & - & - & - \\
\hline Normal & - & - & - & - & - & - & - & - \\
\hline
\end{tabular}

process, a precursor substance is converted to a photoallergen after light absorption of a wavelength corresponding to the triggering action spectrum (AS). Subsequently, IgE immunoglobulins are formed against the photoallergen resulting in an immediate-type hypersensitivity reaction by subsequent contact with the wavelength of the AS [7].

\section{CONCLUSION}

We reported on a development of solar urticaria after the use of UV nail lamps. and hypothesize that the patient was sensitized during the UV nail irradiation process. People need to be aware of the risks associated with the use of UV nail lamps.

\section{Consent}

The examination of the patient was conducted according to the Declaration of Helsinki principles.

\section{REFERENCES}

1. Botto NC, Warshaw EM. Solar urticaria. J Am Acad Dermatol. 2008;59:909-20.

2. Honigsmann H, Hawk JL, Lim HW: Photodermatology. 1st ed. Boca Raton (FL): CRC Press; 2007.

3. Goetze S, Elsner P. Lichturtikaria-Urticaria solaris. J Deuts Dermatol Gesell. 2015;13:1250-4.

4. Haylett AK, Koumaki D, Rhodes LE. Solar urticaria in 145 patients: Assessment of action spectra and impact on quality of life in adults and children. Photodermatol Photoimmunol Photomed. 2018;34:262-8.

5. Shihab N, Lim HW. Potential cutaneous carcinogenic risk of exposure to UV nail lamp: A review. Photodermatol Photoimmunol Photomed. 2018;34:362-5.

6. RiederEA, Tosti A. Cosmetically induced disorders of the nail with update on contemporary nail manicures. J Clin Aesthet Dermatol. 2016;9:39.

7. Kojima M, Horiko T, Nakamura Y, Aoki T. Solar urticaria: the relationship of photoallergen and action spectrum. Arch Dermatol. 1986;122:550-5.

Copyright by Katrien Coninx, et al. This is an open-access article distributed under the terms of the Creative Commons Attribution License, which permits unrestricted use, distribution, and reproduction in any medium, provided the original author and source are credited.

Source of Support: Nil, Conflict of Interest: None declared. 